\title{
Flexibility in timing of the metamorphic molt by fiddler crab megalopae Uca pugilator
}

\author{
Nancy J. O'Connor \\ Department of Marine, Earth and Atmospheric Sciences, North Carolina State University, Raleigh, \\ North Carolina 27695-8208, USA
}

\begin{abstract}
The larvae of many invertebrate taxa can delay metamorphosis for considerable periods of time in the absence of specific stimuli for settlement. This study tested the hypothesis that the duration of the megalopal stage of fiddler crabs can be adjusted by several days depending on the availability of some habitat components. The hypothesis that megalopae can delay the metamorphic molt was tested by comparing the proportion of individuals molting to the first crab instar in aquaria containing only

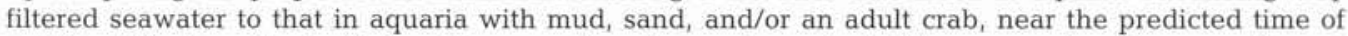
molting. The hypothesis that molting can be advanced was tested by comparing the proportion of sibling larvae molting at intervals throughout the megalopal stage in aquaria containing only filtered seawater or seawater plus an adult crab, mud, and sand. Megalopae delayed molting unless 2 stimuli were present: an adult crab and sediment, either mud or sand. The metamorphic molt was advanced in the presence of both these cues, although contact with the sediment by the adult crab appears necessary for maximal effect. Flexibility in timing of molting and the requirement for more than one cue can increase the chance that megalopae settle and molt to the first crab instar in appropriate adult habitats.
\end{abstract}

\section{INTRODUCTION}

Many marine invertebrates exhibit a planktonic life history stage in which dispersal away from the parental habitat occurs. After this period of dispersal, larvae of many invertebrate taxa settle and metamorphose in response to specific chemical and/or physical stimuli characteristic of the adult habitat (reviewed in Scheltema 1974, Crisp 1984), and can delay metamorphosis in the absence of those stimuli. For example, delay of metamorphosis has been documented in a coral (Richmond 1987), polychaetes (e.g. Wilson, 1968, 1977), gastropods (e.g. Scheltema 1961, Bayne 1965, Switzer-Dunlap 1978, Pechenik 1980, 1986, Paige 1988), a barnacle (Knight-Jones 1953), a bryozoan (Young \& Chia 1981), echinoderms (Strathmann 1978), and a coral reef fish (Victor 1986). In the laboratory, invertebrate larvae remain competent to metamorphose for periods up to several months after spawning (e.g. Birkeland et al. 1971, Kempf 1981, Richmond 1987). For larvae that have not contacted the adult habitat, delay of metamorphosis increases time spent in the plankton, which extends the opportunity for advection to and selection of the appropriate adult habitat (Crisp 1984, Butman 1987).
Most research on larval metamorphosis has been performed on animals with a sessile or sedentary adult stage, for which delay of metamorphosis would be expected because no change in location is possible after settlement occurs. One might anticipate that larvae of motile invertebrates would be less flexibile in timing of metamorphosis if movement to suitable adult habitat after metamorphosis is possible. Until recently, little was known about settlement and metamorphosis of larvae of motile decapod crustaceans in response to habitat cues (Knowlton 1974, but see Cobb 1968, 1970). Adults of 2 species of western Atlantic fiddler crabs inhabiting salt marshes tend to be spatially segregated on the basis of sediment particle size: Uca pugilator is associated with sandy sediment whereas $U$. pugnax inhabits muddier areas (Crane 1975). Fiddler crab megalopae settle in areas occupied by older conspecifics (O'Connor 1990b), so adult crabs and sediments could function as cues stimulating the metamorphic molt from the megalopal stage to the benthic first crab instar. Christy (1989) found that $U$. pugilator megalopae molt to the first crab instar sooner in containers with sediment collected near adult burrows than in containers with seawater alone. In this study I examined the nature of the cue(s) stimulating molting 
of $U$. pugilator megalopae by examining the frequency and timing of molting in response to certain characteristics of the adult habitat, both alone and in combination. The ability to delay the metamorphic molt was tested by comparing the proportion of megalopae molting to the first crab instar in aquaria in which various habitat cues were withheld or presented near the predicted time of molting. The ability to advance molting was tested by examining whether megalopae molted sooner in aquaria containing habitat cues than in aquaria with seawater alone.

\section{MATERIALS AND METHODS}

Ovigerous female Uca pugilator were collected from salt marshes near Beaufort, North Carolina, USA $\left(34^{\circ}\right.$ $43^{\prime} \mathrm{N}, 76^{\circ} 40^{\prime} \mathrm{W}$ ). Crabs and larvae were maintained in an incubator $\left(25^{\circ} \mathrm{C} \pm 1{ }^{\circ} \mathrm{C}\right.$, $14 \mathrm{~h}$ light: $10 \mathrm{~h}$ dark) in glass culture dishes containing $1 \mu \mathrm{m}$ filtered artificial seawater (Instant Ocean brand, $25 \mathrm{ppt}$ salinity $\pm 1 \mathrm{ppt}$ ) and the antibiotic chloramphenicol $\left(5 \mathrm{mg} \mathrm{l}^{-1}\right)$. Zoeae from each brood were reared in groups of 100 to 200 in $20 \mathrm{~cm}$ diameter dishes. Sibling larvae molting to the megalopal stage on the same day after hatching were isolated in dishes for experimentation. Zoeal stages I and II were fed the rotifer Brachionus plicatilis; stage III zoeae were fed a mixture of rotifers and newly-hatched brine shrimp nauplii (Artemia sp.); and zoeal stages IV and $\mathrm{V}$ and megalopae were fed only Artemia nauplii. Each day larvae were transferred to bowls with fresh seawater and fed ad libitum.

Delay of molting. Six days after molting to the megalopal stage, sibling larvae were placed in groups of 8 to 10 in clear polycarbonate aquaria $(28 \mathrm{~cm}$ long $\times 20 \mathrm{~cm}$ wide $\times 16 \mathrm{~cm}$ high) containing 1.51 of $1.2 \mu \mathrm{m}$ filtered aged ( $>1 \mathrm{wk}$ ) natural seawater $(25 \mathrm{ppt}$ $\pm 1 \mathrm{ppt}$ ) collected from Bogue Sound, Carteret County, North Carolina. Groups of megalopae were randomly assigned to 1 of 7 treatments: (1) 'control' = filtered natural seawater (FNS) only; (2) 'adult' $=$ FNS +1 adult Uca pugilator isolated in a 11 plastic container with windows cut near the bottom and covered with fine-mesh netting $\left(0.08 \mathrm{~mm}^{2}\right.$ apertures $)$, through which seawater could pass; (3) 'mud' $=$ FNS +4 to $5 \mathrm{ml}$ surface mud collected from a marsh containing mostly $U$. pugnax, sieved through $1 \mathrm{~mm}$ mesh and divided into 5 lumps on the bottom of the aquarium; (4) 'sand' = FNS $+3 \mathrm{ml}$ sieved $(1 \mathrm{~mm}$ mesh) dredgespoil sand sprinkled over the bottom of the aquarium; (5) 'adult + mud'; (6) 'adult + sand'; and (7) 'adult Uca pugnax ${ }^{\prime}=$ FNS + one adult $U$. pugnax isolated as described above. Megalopae from a total of 7 broods were used in the experiments. Within a brood, the number of megalopae at the same developmental stage was insufficient to subject siblings to all treatments. However, for 5 out of the 7 broods sibling larvae were divided among at least 4 treatments including the control.

Aquaria were covered with sheets of plexiglas, provided with aeration, and placed on a table in a laboratory $\left(25^{\circ} \mathrm{C} \pm 2{ }^{\circ} \mathrm{C}\right)$ that received diffuse window light, plus additional fluorescent light during (daylight) working hours. The aquaria were arranged haphazardly on the table to minimize possible effects of local microclimate on treatment position. Each day 200 to 300 Artemia nauplii were added to each aquarium to provide food for the megalopae.

Experiments were terminated after $72 \mathrm{~h}$ because prior work (O'Connor 1990a) indicated that ca $50 \%$ of megalopae should have molted to the first crab instar by this time, even in cultures maintained in artificial seawater. Timing of molting was no different in filtered natural seawater than in artificial seawater $\left(\mathrm{O}^{\prime} \mathrm{Connor}\right.$ unpubl.). Megalopae and metamorphosed crabs were removed from aquaria by pipetting. Crabs hidden in sediments, where present, were retrieved by sieving sediments through a $0.5 \mathrm{~mm}$ mesh screen. Using a dissecting microscope, I counted numbers of living megalopae, living crabs, and dead specimens. The proportion of megalopae molting within an aquarium was calculated on the basis of the number of individuals alive at the end of the experiment because not all dead individuals could be recovered, and some carcasses had decomposed so that it was difficult to tell whether metamorphosis had occurred. A 1-way analysis of variance of arcsin-transformed proportions was used to determine whether there were significant ( $\mathrm{p} \leq$ 0.05 ) differences among treatments in the proportion of megalopae molting to the first crab instar.

Advance of molting. One day after molting to the megalopal stage, larvae were placed in groups of ca 10 individuals in aquaria described above. Sibling larvae were paired in 'control' aquaria containing 1.51 of $1.2 \mu \mathrm{m}$ filtered aged natural seawater $(25 \mathrm{ppt} \pm 1 \mathrm{ppt})$ collected near Pivers Island, Carteret County, and in 'experimental' aquaria containing 1.51 of FNS + mud + sand + one adult Uca pugilator as described above. Aquaria were covered with plexiglas, provided with aeration, and placed in an incubator $\left(25^{\circ} \mathrm{C} \pm 1{ }^{\circ} \mathrm{C}\right.$, $14 \mathrm{~h} \mathrm{~L}: 10 \mathrm{~h} \mathrm{D}$ ). Approximately 400 Artemia nauplii were added to each aquarium every second day.

Experiments in paired aquaria were terminated 3,6, or $9 \mathrm{~d}$ after the day of molt to megalopa, in the manner described above. During prior larval rearing studies in the absence of potential cues I observed that no megalopae molted to the first crab instar within $3 \mathrm{~d}$ after molting to the megalopal stage, and many megalopae molted within $9 \mathrm{~d}$. Therefore, I hypothesized that in the presence of cues advance of molting would be detect- 
able by $6 \mathrm{~d}$ after larvae molted to megalopa, and that the proportion of molted individuals would be greater in the ' $6 \mathrm{~d}$ experimental' than in the ' $6 \mathrm{~d}$ control' aquaria. This hypothesis was tested with a 1-tailed, paired $\mathrm{t}$-test and a 1-sided sign test on the difference in the proportion of metamorphosed crabs in the control and experimental aquaria.

\section{RESULTS}

\section{Delay of molting}

In each treatment, including the control, an average of at least $50 \%$ of the individuals successfully molted (Fig. 1). Although there was no significant difference among treatments in the proportion of megalopae molting to the first crab instar (overall ANOVA $p=0.16$ ),

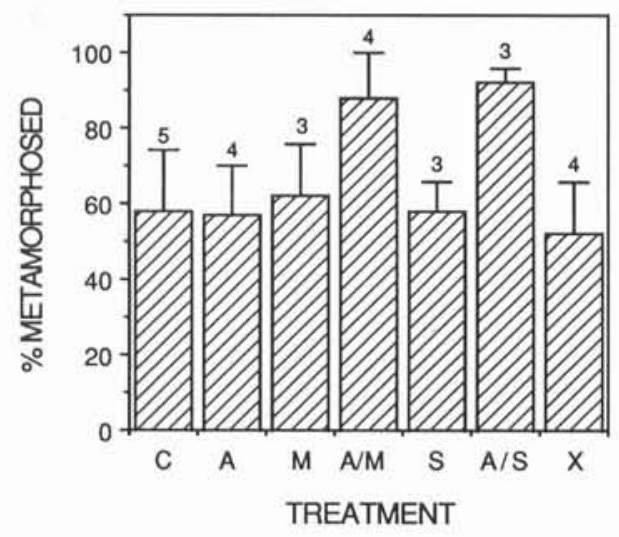

Fig. 1. Uca pugilator, Mean percent megalopae that molted to the first crab instar in aquaria containing (C) filtered natural seawater (control), (A) adult $U$. pugilator, (M) mud, (A/M) adult + mud, (S) sand, (A/S) adult + sand, (X) adult $U$. pugnax. See text for description of treatments. Error bars $=+1$ standard error; numbers above the error bars indicate the number of replicates per treatment

there was a trend toward a higher incidence of molting in the treatments containing both an adult conspecific and sediment, either mud or sand. Based on the nature of the design of the experiment, where 2 treatments ('adult + mud' and 'adult + sand') combined cues present in other treatments, a post-hoc contrast was performed. The contrast consisted of comparing the proportion of megalopae molting in the 'adult + mud' and 'adult + sand' treatments versus that in the 'control', 'adult', 'mud', and 'sand' treatments. Significantly more individuals molted in the treatments containing an adult crab plus sediment (mud or sand) than in the other treatments $(\mathrm{p}=0.0089)$. The average mortality/ aquarium was $13.5 \%$ (range $=0$ to $60 \%$ ), and was approximately the same in each treatment (average mortality/treatment $=13.9 \%$, range $=6.4$ to $23.5 \%$ ).

\section{Advance of molting}

No molting occurred in either the $3 \mathrm{~d}$ control or the $3 \mathrm{~d}$ experimental treatments, and a large proportion of individuals underwent the metamorphic molt in both the $9 \mathrm{~d}$ control and experimental treatments (Table 1). There was a trend of a greater proportion of megalopae

Table 1. Uca pugilator. Proportion of megalopae that molted to the first crab instar in control aquaria (C) containing filtered seawater and in experimental aquaria (E) containing seawater plus an adult $U$. pugilator, sand, and mud. Experiments were terminated either 3,6 , or $9 \mathrm{~d}$ after the larvae had molted to the megalopal stage. Dashes indicate that those particular experiments were not done

\begin{tabular}{|cccccccc|}
\hline \multirow{2}{*}{$\begin{array}{c}\text { Brood } \\
\text { No. }\end{array}$} & \multicolumn{9}{c|}{ Day experiment terminated } \\
& C & E & \multicolumn{2}{c|}{ Day 6} & \multicolumn{2}{c|}{ Day 9} \\
& C & E & C & E \\
\hline 37 & 0 & 0 & 0.12 & 1.00 & 0.75 & 1.00 \\
40 & 0 & 0 & 0.50 & 0.62 & - & - \\
41 & 0 & 0 & 0 & 0.17 & - & - \\
42 & 0 & 0 & 0.25 & 0.33 & 1.00 & 1.00 \\
43 & - & - & 0.25 & 0.25 & - & - \\
\hline
\end{tabular}

molting to the first crab instar in the $6 \mathrm{~d}$ experimental aquaria than in the $6 \mathrm{~d}$ control aquaria $(0.10>\mathrm{p}>0.05$ for both the paired t-test and the sign test) (Table 1). Mortality, ranging from 0 to $80 \%$, was higher in these experiments than in those testing for delay of molting. There was no apparent relationship between mortality and brood or treatment, except that mortality was lowest in the $3 \mathrm{~d}$ aquaria. The average mortality in the $6 \mathrm{~d}$ control aquaria was $61 \%$, and in the $6 \mathrm{~d}$ experimental aquaria it was $41 \%$.

\section{DISCUSSION}

This study documents flexibility in the timing of molting by Uca pugilator megalopae, under certain conditions and within a defined time scale. By partitioning treatments, this study also suggests that more than one cue must be present to stimulate the metamorphic molt: more megalopae molted to the first crab instar in the presence of both an adult crab and sediment than with either cue alone (Fig. 1). The requirement that both an adult conspecific and sediment particles be present to stimulate metamorphosis has been reported for other soft-sediment dwelling animals (Suer \& Phillips 1983, Rice 1986).

Christy (1989) examined the length of the megalopal stage in the presence of fresh sediment scraped from around adult burrows. In the 'adult + sand' and 'adult + mud' treatments in the present experiments the adult 
crabs and sediment were physically separated, and I assumed that any water-borne cue released by the adult crab would diffuse through the water and be adsorbed to the sediment surface. Many chemical stimuli of settlement and metamorphosis are known to function when adsorbed to a surface (Crisp 1984, Rittschof \& Bonaventura 1986). Because megalopae molted to the first crab instar sooner in Christy's (1989) experiments than in those reported here, it appears that sediment that has been in direct contact with a crab, perhaps through feeding, burrowing or deposition of fecal pellets, provides a stronger stimulus for molting than does sediment containing a cue adsorbed from the surrounding water.

Within a brood, variability in the length of the megalopal stage (or the planktonic stage in general) enhances the geographical spread of sibling larvae and increases the chance that at least some siblings will be transported to adult habitats (Strathmann 1974, Sandifer \& Smith 1979, Sulkin \& Van Heukelem 1986). In Uca pugilator variability exists in the duration of the megalopal stage, both among broods (Table 1; 'Day 6' data), and within broods. Although ca $50 \%$ of $U$. pugilator megalopae molt to the first crab instar by $9 \mathrm{~d}$ after molting to megalopa (Fig. 1), some siblings remain in the megalopal stage in laboratory cultures up to several weeks before molting (O'Connor 1990a). Christy (1989) reported apparently 'pathological' behavior in larvae molting late in the megalopal stage, but I have found that these late-molting individuals pass through early crab instars at the same rate as siblings that molted early in the megalopal stage (O'Connor 1990a), indicating that late metamorphosis has no negative effect on the subsequent development of benthic instars.

Recent work has shown that megalopae of some decapod crustaceans settle gregariously in adult habitats (Jensen 1989, O'Connor 1990b), even though they are motile after metamorphosing and could make additional habitat choices. Thus, although megalopae incur the risk of predation by remaining in the plankton, by delaying the metamorphic molt they increase their chance of encountering habitat suitable for settlement, a benefit that appears to outweigh any inherent risks. Once this habitat is contacted, molting to the benthic form can be advanced.

Acknowledgements. I thank L. Levin, D. Kamykowski, and T. and D. Wolcott (NCSU) and J. Costlow and D. Rittschof (Duke University Marine Laboratory) for the use of their supplies and equipment. I am grateful to A. Powell and C. Lewis (National Marine Fisheries Service, NOAA, Beaufort, NC) for initial stocks of rotifers and algae, and to C. Brownie, T. Miller, and L. Crowder (NCSU) for help with the statistical analyses. This study was partially supported by a research grant from the Lerner-Gray Fund for Marine Research of the American Museum of Natural History, a Grant-in-Aid of Research from
Sigma Xi, supplies from T. Hines of the Smithsonian Environmental Research Center, and funds from the Dept. of Marine, Earth and Atmospheric Sciences, NCSU. T. Wolcott, D. Wolcott, L. Levin, L. Crowder, G. Thayer, J. Christy, and an anonymous reviewer provided valuable critiques of the manuscript. This study represents a portion of a dissertation submitted in partial fulfillment of requirements for the $\mathrm{Ph}$. D. degree at North Carolina State University.

\section{LITERATURE CITED}

Bayne, B. L. (1965). Growth and the delay of metamorphosis of the larvae of Mytilus edulis (L.). Ophelia 2: 1-47

Birkeland, C., Chia, F.-S., Strathmann, R. R. (1971). Development, substratum selection, delay of metamorphosis and growth in the seastar, Mediaster aequalis Stimpson. Biol. Bull. mar. biol. Lab., Woods Hole 141: 99-108

Butman, C. A. (1987), Larval settlement of soft-sediment invertebrates: the spatial scales of pattern explained by active habitat selection and the emerging role of hydrodynamical processes. Oceanogr. mar. Biol. A. Rev, 25: 113-165

Christy, J. H. (1989). Rapid development of megalopae of the fiddler crab Uca pugilator reared over sediment: implications for models of larval recruitment. Mar. Ecol. Prog. Ser. 57: 259-265

Cobb, J. S. (1968). Delay of moult by the larvae of Homarus americanus. J. Fish. Res. Bd Can. 25: 2251-2253

Cobb, J. S. (1970). Effect of solitude on time between fourth and fifth larval molts in the American lobster (Homarus americanus). J. Fish. Res. Bd Can. 27: 1653-1655

Crane, J. (1975). Fiddler crabs of the world. Princeton University Press, Princeton, New Jersey

Crisp, D. J. (1984). Overview of research on marine invertebrate larvae, 1940-1980. In: Costlow, J. D., Tipper, R. C. (eds.) Marine biodeterioration: an interdisciplinary study. Naval Institute Press, Annapolis, p. 103-126

Jensen, G. C. (1989). Gregarious settlement by megalopae of the porcelain crabs Petrolisthes cinctipes (Randall) and $P$. eriomerus Stimpson. J. exp. mar. Biol. Ecol. 131: 223-231

Kempf, S. C. (1981). Long-lived larvae of the gastropod Aplysia juliana: do they disperse and metamorphose or just slowly fade away? Mar. Ecol. Prog. Ser. 6: 61-65

Knight-Jones, E. W. (1953). Laboratory experiments on gregariousness during settling in Balanus balanoides and other barnacles. J. exp. Biol. 30: 584-598

Knowlton, R. E. (1974). Larval developmental processes and controlling factors in decapod Crustacea, with emphasis on caridea. Thalassia jugosl. 10: 138-158

O'Connor, N. J. (1990a). Morphological differentiation and molting of juvenile fiddler crabs (Uca pugilator and $U$. pugnax). J. crust. Biol. 10: in press

O'Connor, N. J. (1990b). Larval settlement and juvenile recruitment in fiddler crab populations. Ph.D. dissertation, North Carolina State University, Raleigh, North Carolina

Paige, J. A. (1988). Biology, metamorphosis and postlarval development of Bursatella leachii plei Rang (Gastropoda: Opisthobranchia). Bull. mar. Sci. 42: 65-75

Pechenik, J. A. (1980). Growth and energy balance during the larval lives of three prosobranch gastropods. J. exp. mar. Biol. Ecol. 44: 1-28

Pechenik, J. A. (1986). Field evidence for delayed metamorphosis of larval gastropods: Crepidula plana Say, C. fornicata (L.), and Bittium alternatum (Say). J. exp. mar. Biol. Ecol. 97: 313-319

Rice, M. E. (1986). Factors influencing larval metamorphosis in 
Golfingia misakiana (Sipuncula). Bull. mar. Sci. 39: 362-375

Richmond, R. H. (1987). Energetics, competency, and longdistance dispersal of planula larvae of the coral Pocillopora damicornis. Mar. Biol. 93: 527-533

Rittschof, D., Bonaventura, J. (1986). Macromolecular cues in marine systems. J. chem. Ecol. 12: 1013-1023

Sandifer, P. A., Smith, T. I. J. (1979). Possible significance of variation in the larval development of palaemonid shrimp. J. exp. mar. Biol. Ecol. 39: 55-64

Scheltema, R. S. (1961). Metamorphosis of the veliger larvae of Nassarius obsoletus (Gastropoda) in response to bottom sediment. Biol. Bull. mar. biol. Lab., Woods Hole 120: 92-109

Scheltema, R. S. (1974). Biological interactions determining larval settlement of marine invertebrates. Thalassia jugosl. 10(1/2): 263-296

Strathmann, R. R. (1974). The spread of sibling larvae of sedentary marine invertebrates. Am. Nat. 108: 29-44

Strathmann, R. R. (1978). Larval settlement in echinoderms. In: Chia, F.-S., Rice, M. E. (eds.) Settlement and metamorphosis of marine invertebrate larvae. Elsevier NorthHolland, New York, p. 235-246

This article was presented by Dr R. B. Forward, Beaufort, N. Carolina, USA
Suer, A. L., Phillips, D. W. (1983). Rapid, gregarious settlement of the larvae of the marine echiuran Urechis caupo Fisher \& MacGinitie 1928. J. exp. mar. Biol. Ecol. 67: 243-259

Sulkin, S. D., Van Heukelem, W. F. (1986). Variability in the length of the megalopal stage and its consequence to dispersal and recruitment in the portunid crab Callinectes sapidus Rathbun. Bull. mar. Sci. 39: 269-278

Switzer-Dunlap, M. (1978). Larval biology and metamorphosis of aplysiid gastropods. In: Chia, F.-S., Rice, M. E. (eds.) Settlement and metamorphosis of marine invertebrate larvae. Elsevier North-Holland, New York, p. 197-206

Victor, B. C. (1986). Delayed metamorphosis with reduced larval growth in a coral reef fish (Thalassoma bifasciatum). Can. J. Fish. Aquat. Sci. 43: 1208-1213

Wilson, D. P. (1968). The settlement behaviour of the larvae of Sabellaria alveolata (L.). J. mar. biol. Ass. U.K. 48: 387-435

Wilson, D. P. (1977). The distribution, development and settlement of the sabellarian polychaete Lygdamis muratus (Allen) near Plymouth. J. mar. biol. Ass. U.K. 57: 761-792

Young, C. M., Chia, F.-S. (1981). Laboratory evidence for delay of larval settlement in response to a dominant competitor. Int. J. invertebr. Reprod. 3: 221-226

Manuscript first received: February 2, 1990

Revised version accepted: September 3, 1990 